\section{Reply to Brijwal et al}

To the Editor-We thank Brijwal and colleagues for their letter on our study [1]. We also appreciate their insights and the valuable data reported in their letter. We agree that these new data from India affirm our finding of an apparent transition in the epidemiology of herpes simplex virus type 1 (HSV-1) in Asia, with a growing role for this virus as a sexually transmitted infection. Such current data from India are very timely, given the paucity of data from this country, on both genital ulcer disease (GUD) and genital herpes.

We further seize this opportunity to highlight the unexplained (relatively) low seroprevalence in Indian-subcontinent populations [1-3]; the pooled mean seroprevalence in our study was estimated at 93\% in adults in China, but only at $67 \%$ in adults in India [1]. While the reason(s) behind the unexpectedly low seroprevalence in India remain unknown, this level of seroprevalence should logically entail considerable contribution for HSV-1 in GUD and genital herpes. A significant fraction of youth should be reaching sexual debut uninfected, and thus potentially at risk of acquiring HSV-1 sexually.
We could not, however, identify any recent and type-specific data from India for both GUD and genital herpes to validate this conjecture. We are thus delighted to see these newly reported data from India affirming a considerable role for HSV-1 in both GUD and genital herpes, and more so for first-episode genital herpes. We join Brijwal and colleagues in stressing the need for more studies and surveillance for HSV-1 seroprevalence as well as GUD and genital herpes, to clarify better HSV-1 transmission and to assess trends, in a context of an evolving epidemiology.

\section{Note}

Potential conflicts of interest. All authors: No reported conflicts of interest. All authors have submitted the ICMJE Form for Disclosure of Potential Conflicts of Interest. Conflicts that the editors consider relevant to the content of the manuscript have been disclosed.

\section{Lara Khadr, ${ }^{1,2}$ Manale Harfouche, Ryosuke Omori, ${ }^{3}$ Guido Schwarzer,} Hiam Chemaitelly, ${ }^{1}$ and Laith J. Abu-Raddad ${ }^{1,5}$

${ }^{1}$ Infectious Disease Epidemiology Group, Weill Cornell Medicine-Qatar, Cornell University, Qatar Foundation-

Education City, Doha; ${ }^{2}$ Department of Epidemiology, University of Michigan School of Public Health, Ann Arbor;

${ }^{3}$ Division of Bioinformatics, Research Center for Zoonosis Control, Hokkaido University, Sapporo, Japan; ${ }^{4}$ Institute of Medical Biometry and Statistics, Faculty of Medicine and Medical Center, University of Freiburg, Germany; and
${ }^{5}$ Department of Healthcare Policy and Research, Weill Cornel Medicine, Cornell University, New York, New York

\section{References}

1. Khadr L, Harfouche M, Omori R, Schwarzer G, Chemaitelly H, Abu-Raddad LJ. The epidemiology of herpes simplex virus type 1 in Asia: systematic review, meta-analyses, and meta-regressions [manuscript published online ahead of print 18 July 2018]. Clin Infect Dis 2018. doi:10.1093/cid/ ciy562.

2. Nasrallah GK, Dargham SR, Harfouche M, AbuRaddad LJ. Seroprevalence of herpes simplex virus type 1 and 2 in Filipino and Indian migrant populations in Qatar: a cross-sectional survey on men blood donors. East Mediterr Health J 2018. In press

3. Nasrallah GK, Dargham SR, Mohammed LI, AbuRaddad LJ. Estimating seroprevalence of herpe simplex virus type 1 among different Middle East and North African male populations residing in Qatar. J Med Virol 2018; 90:184-90.

Correspondence: L. J. Abu-Raddad, Infectious Disease Epidemiology Group, Weill Cornell Medicine-Oatar, Oatar Foundation-Education City, PO Box 24144, Doha, Oatar (lja2002@qatar-med.cornell.edu).

Clinical Infectious Diseases ${ }^{\circledR} \quad$ 2018;XX(XX):1-1

(C) The Author(s) 2018. Published by Oxford University Press for the Infectious Diseases Society of America. All rights reserved. For permissions, e-mail: journals.permissions@oup.com. 